\title{
Spatial survey of tephra deposits in the middle Lahn valley (Hesse, Germany)
}

\author{
Collin J. Weber, Volker M. H. Dickhardt, and Stefan Harnischmacher \\ Department of Geography, Philipps-University Marburg, Marburg, 35032, Germany
}

Correspondence: Collin J. Weber (collin.weber@geo.uni-marburg.de)

Relevant dates: $\quad$ Received: 26 March 2021 - Revised: 11 May 2021 - Accepted: 1 June 2021 Published: 1 July 2021

How to cite: Weber, C. J., Dickhardt, V. M. H., and Harnischmacher, S.: Spatial survey of tephra deposits in the middle Lahn valley (Hesse, Germany), E\&G Quaternary Sci. J., 70, 165-169, https://doi.org/10.5194/egqsj-70-165-2021, 2021.

\section{Introduction}

Tephra deposits and especially Laacher See tephra (LST) deposits resulting from the Laacher See eruption $(12.9 \mathrm{ka})$ are an important stratigraphic marker for the Allerød period in central Europe (van den Bogaard and Schmincke, 1995). Within the central German low mountain range (Rhenish Massif and eastern areas) the LST was found within soils (initial deposits, sheltered slope positions) and valleys (relocated deposits) (Bos and Urz, 2003; Hahn and Opp, 2005). The Niederweimar gravel quarry, located on the lower terrace in the middle reach of the Lahn River valley south of Marburg (Hesse, Germany), is known for its high-resolution stratigraphy of Quaternary gravel deposits and late glacial, as well as Holocene, floodplain fines (Lomax et al., 2018). This particular stratigraphy is mainly achieved by the up to $2 \mathrm{~m}$ thick LST deposits, which consist of pure LST beds and a multitude of fine LST bands (partly interbedded with black sands or interrupted by clay bands). The origin of the LST in the floodplain is attributed to an extensive deposition (aeolian, directly in the floodplain), as well as later fragmentation of the tephra deposits by surface erosion and renewed deposition of LST from the catchment area through changing river systems (Bos and Urz, 2003; Lomax et al., 2018). The surroundings of the gravel quarry are also rich in archaeological finds reaching more or less continuously from the Mesolithic (11.7 to $7.5 \mathrm{ka}$ ) to the Middle Ages (Bos and Urz,
2003; Lomax et al., 2018). Further well-summarized information about the situation within the Niederweimar gravel quarry can be found in Lomax et al. (2018) or on the website of the archaeological survey of Hesse (https://lfd.hessen.de/, last access: 21 March 2021).

The evidence of LST in the Lahn valley, as in other valley sediments, is often limited to gravel pits (other larger excavations). These pits and their profiles offer very good insights (e.g. detailed lithostratigraphic description of profiles), but they are always limited to a comparatively small spatial section of the entire floodplain (gravel pit area). Therefore, the objective of the presented study is to provide a spatial survey of LST deposits in the middle Lahn valley, covering the entire floodplain cross section. The following two questions form the focus of the spatial survey. (1) How is the lateral and vertical extension of the LST deposits within the Lahn valley floodplain? (2) Does the spatial distribution provide overarching information about the deposition dynamics of the LST? For this purpose, a transect-based survey with qualitative analysis of LST grains based on density separation and visual identification (stereomicroscope) was applied.

\section{Methods}

Survey and sampling of tephra samples was conducted at three floodplain transects (including active floodplain zone and lower terrace) in the south of Niederweimar gravel 
quarry where the floodplain shows one of its greatest transverse expansions (Fig. 1). Transects cover a maximum width of $973.9 \mathrm{~m}$ and are at $170.9 \mathrm{~m}$ a.s.l. (above sea level) with a height difference of $\pm 1.4 \mathrm{~m}$. Sampling was carried out with the help of a hand auger (Pürckhauer, $\varnothing 2 \mathrm{~cm}, 2 \mathrm{~m}$ depth) and pile core probing (Ø6-8 cm, $3 \mathrm{~m}$ depth). Soil properties and stratigraphy were documented in the field according to the national standard soil classification scheme (KA5, Ad-hoc AG Boden, 2005). Tephra-containing layers were identified visually (visible tephra grains) or by smeary consistence (owing to higher contents of allophane) (Jahn et al., 2006), proportion documented (percentage of tephra grains estimated by area according to KA5), and extracted for further analysis.

Samples for method validation and as comparison material (reference samples) were taken from a recently excavated profile (32U 480710 5621590) in the Niederweimar gravel quarry, which was excavated during archaeological work. The profile consists of Holocene floodplain loams (silt to sandy loam) above four LST layers (sandy loam, partwise alternating with black sands and ripple) and flood loam (late Pleistocene) at the base (Fig. 2). Three samples were taken from the upper (LST bands mixed with sandy loam), middle (thick LST bands, between black sands) and lower (LST bands interrupted by black sands with ripple shapes) parts of the LST layer (Fig. 2).

Reference samples and samples from the transects were dried at $100^{\circ} \mathrm{C}$ (drying chamber) under weight loss control, subsequently carefully ground, and sieved to $<2 \mathrm{~mm}$ (stainless steel sieve, Retsch, Haan, Germany). Subsample material (20g per sample) was then mixed with $150 \mathrm{~mL}$ saturated $\mathrm{NaCl}$ solution (density adjusted, $\rho=1.2 \mathrm{~g} \mathrm{~cm}^{-3}$ ) within glass beakers, stirred (1 min, magnetic stirrer) and allowed to sediment for $20 \mathrm{~min}$. This allows the tephra grains to be separated from other mineral components (sand to clay grains), despite the heavy minerals contained (Lomax et al., 2018), because the grains float in the dry state due to their many cavities (volcanic origin). The floating tephra grains were then sieved to $>50 \mu \mathrm{m}$ (Atechnik, Leinburg, Germany) to separate clay and/or silt particles and filtered by vacuum filtration (cellulose filter, LLG-Labware, Meckenheim, Germany) to rinse out remaining salts. Dried filters were visually examined using a stereomicroscope (Motic SMZ-161 TL, Motic, Hong Kong). From the reference samples, 30 randomly selected tephra grains were extracted and measured (Moticam, Motic, Hong Kong). Samples from the transects were inspected according to the presented method, and the presence of tephra grains or their fragments was considered a positive finding. In addition, 19 samples containing proven LST were selected, and the particle size distribution was determined according to DIN ISO 11277 (2002) and the integral suspension pressure method (Durner et al., 2017).

\section{Results and discussion}

In total 56 tephra containing stratigraphically distinguishable layers were identified and sampled. Qualitative tephra analyses within the laboratory show a positive rate of $69.6 \%$ in which case tephra could be detected under the microscope for the 56 samples. In $30.4 \%$ of the layers, no tephra grains or larger fragments could be found even if the Greasing effect occurred in the field. The applied method is therefore suitable for qualitative detection, is fast and inexpensive, and can be extended by other methods such as mineral analysis and dating. Tephra grains occur usually entire with greybrown to greenish colours, clear holes and glassy surface structure (Fig. 2). The length to width ratio of the grains from a random sample of 30 grains comprises an average length of $782.7( \pm 288.4) \mu \mathrm{m}$ and width of $557.12( \pm 179.5) \mu \mathrm{m}$. Grain surface and average and maximum length $(1565.9 \mu \mathrm{m})$ correspond clearly to the reference samples (same colour, holes and glassy structure) with an average length of 724.3 $( \pm 245.6) \mu \mathrm{m}$.

Tephra layers come up at average depths of $68.6 \mathrm{~cm}$ below surface and end at average depths of $166.5 \mathrm{~cm}( \pm 46.3 \mathrm{~cm})$. Tephra layers have thicknesses from 6.0 up to $132.0 \mathrm{~cm}$ with an average thickness of $52.0 \mathrm{~cm}$ (Figs. $1 \mathrm{~b}$ and 2). Grain size analyses of tephra-containing layers has a mean distribution of $30.2 \%$ clay, $46.8 \%$ silt and $23.1 \%$ sand. However, the share of sand is ranging between $2.7 \%$ and $57.9 \%$, resulting in the samples comprising the grain size classes clay, silty clay, silty clay loam to silt loam (outliers within loam and sandy loam), and they are thus very heterogeneous.

Stratigraphic classification of tephra layers corresponds to the findings of our reference profile and other profiles within the Niederweimar quarry (e.g. Lomax et al., 2018): The tephra layers are covered by Holocene floodplain sediments (floodplain loams, silty loams) and rarely with single clay layers or isolated gravel deposits. The lowermost tephra layers, partly with the same pattern of banding (LST bands and black sands) (Fig. 2), however, are only poorly visible within the drill sample in contrast to quarry profiles. Below the tephra, a thin band (approx. $5 \mathrm{~cm}$ ) of sand with gravel occurs, followed by a thick layer of clay (dark and rich in organic matter), before the gravel deposits of the lower terrace begin.

Regarding the vertical and lateral spatial distribution of tephra layers it can be stated that it is present nearly all over the floodplain area of the middle Lahn valley. The interpolation of the upper and lower tephra boundaries (Fig. 1b) shows that it is independent of the terrain surface today. This indicates that the tephra follows the morphology of Pleistocene gravel and flood loam deposits, as observed within the quarry (reference profile). The tephra is missing at the edge of the floodplain (drill point 101a: transition to the lower slope, colluvial formation), in the area of the active floodplain (drill points 108a and 2010a: river erosion) and in parts with inactive channel situations (drill point 304b) where Pleistocene 


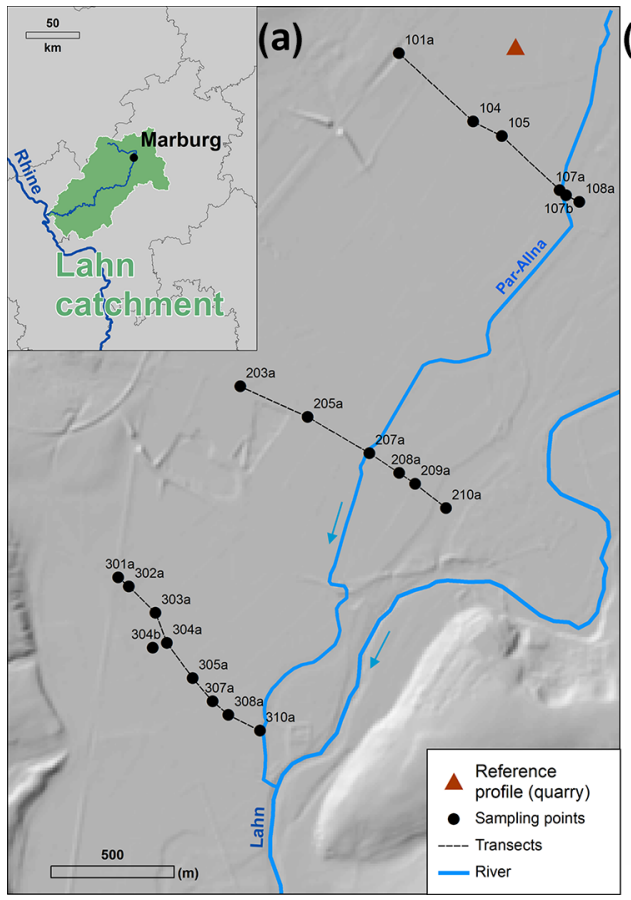

(b)
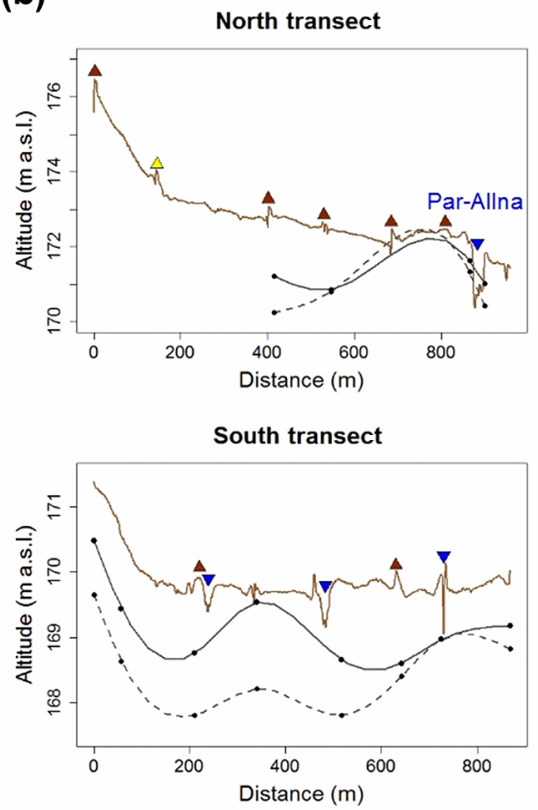

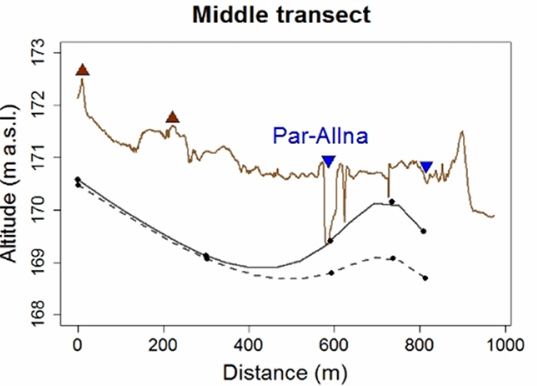

Terrain surface

Depth of upper tephra-layer

boundary

$\checkmark$ Depth of lower tephra-layer

boundary

- Depth layer boundaries (confirmed with

- boreholes)

$\Delta$ Dirt road

$\nabla$ Creek

$\Delta$ Road (K62) between Niederwalgern and Argenstein

Figure 1. Study area located within the Lahn River catchment in the south of Marburg and transects with interpolated upper and lower tephra boundaries. (a) Transects with sampling points (drill cores) and location of reference profile within the quarry. (b) Interpolated upper and lower tephra boundaries under terrain surface. Deviation in the interpolation (lower limit) results from large distances between the boreholes (no borehole due to missing permission). Data basis: Hessian State Agency for Soil Management and Geoinformation (HVBG, 2019).
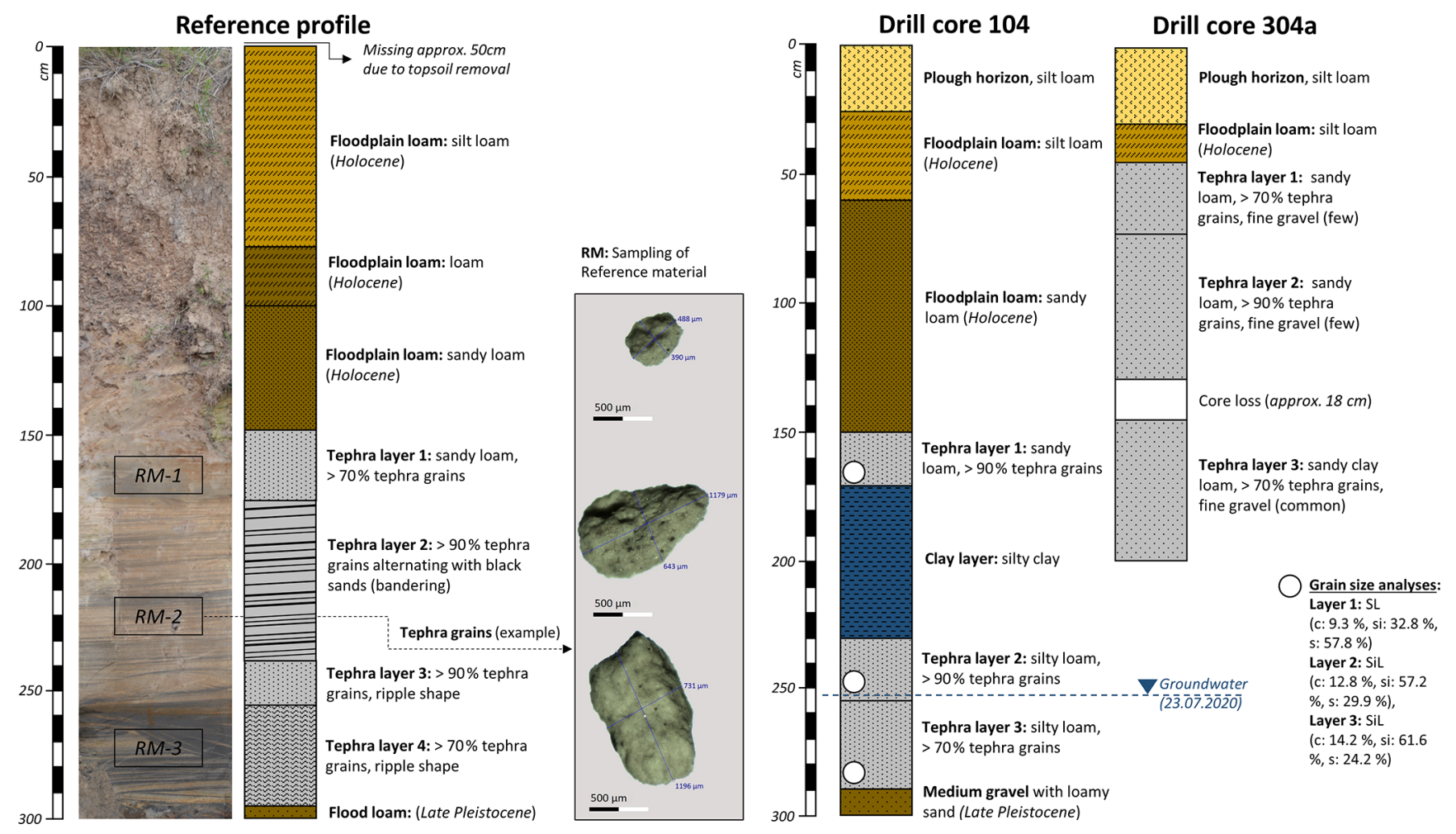

Figure 2. Lithological description of reference profile (with exemplary separated tephra grains) and exemplary drill cores (104: north transect; 304a: south transect). 
gravel structures are found directly below the terrain surface. The interpolation also indicates, despite spatial inaccuracies, that the position of the lower tephra border allows for a partwise reconstruction of the terrain surface that existed at the time of deposition, with structures of various flow channels preformed in the Pleistocene.

Regarding the depositional conditions for LST within the Lahn River valley the heterogeneous grain size distribution indicates slow to medium flow velocities (clay-silt deposition) during LST deposition. From the findings presented in this report an area-wide deposition of LST in the middle Lahn valley can be assumed, which encompasses the entire width of the floodplain. LST deposits seem to follow the structure of preformed Pleistocene flow channels throughout the floodplain, as already stated for the quarry profiles (Bos and Urz, 2003; Lomax et al., 2018). The heterogeneous grain size distribution, banding of the LST with sandy loam intermediate layers and the absence of LST in the floodplain margin and active floodplain area (erosion) indicate fluvial deposition. Therefore, it can be concluded that the LST deposits originate from the entire upper catchment area and have been reworked within the entire floodplain.

\section{Conclusion}

The present survey shows an area-wide occurrence of LST deposits within the floodplain area of the middle Lahn valley. Vertical extension of LST deposits seems to follow preformed Pleistocene channel structures. The spatial distribution of LST deposits allows for an overreaching consolidation of former findings regarding the LST deposition and origin: LST deposition took place during the Allerød period, when river systems change due to climatic shifts. The findings presented here support the assumption that large quantities of LST have been deposited and relocated in the floodplain, which must originate mainly from fluvial transport originating from the entire catchment area instead of direct aeolian deposition. The widespread distribution of the sediments alone suggests large quantities of LST. Even though the analyses of quarry profiles have provided major insights about LST deposition in previous research, the presented results offer a spatial view that goes beyond this and contribute to the reconstruction of preformed Pleistocene channel structures. As the pure LST deposits occurring in the Lahn valley represent a special stratigraphic unit, further research should aim to clarify the details of LST deposition, exact sequence of events and former river system characteristics by a holistic spatial methodological approach in the future and also in other regions. In relation to the more than 11000 years of documented settlement history within the study area, the immense occurrence and widespread distribution of tephra deposits may have influenced land use and cultivation opportunities across different cultures. Despite the fact that the aeolian deposition, fluvial transport and redeposition of a mas- sive amount of tephra at the beginning of the Holocene had an immense impact on the landscape and humans at that time, the deposits that are still present today provide an enhancement of the soil properties. In contrast to other valleys without these amounts of tephra, the alluvial floodplain soils of the middle Lahn valley can probably have a higher water holding capacity in dry periods, as well as a positive influence on groundwater reserves due to the tephra grains even if their soil cultivation might be affected by compaction (stagnic properties, stagnosols) in some places. Further interdisciplinary research from the fields of soil science and archaeology should examine the considerations and effects of the tephra deposits beyond their use as stratigraphic markers.

Data availability. The digital elevation model is used with the permission of the Hessian State Agency for Soil Management and Geoinformation. All further data generated during this study are included in this article or are available from the corresponding author upon request.

Author contributions. CJW conceived the project. CJW and VMHD collected reference samples and performed the profile description in the field. VMHD performed the spatial survey and further sample collection. CJW and VMHD have developed, tested and applied the density separation method for tephra grain extraction. VMHD performed the laboratory work. All authors contributed to the interpretation of the data and have contributed to the manuscript's initial and review processes.

Competing interests. The authors declare that they have no conflict of interest.

Disclaimer. Publisher's note: Copernicus Publications remains neutral with regard to jurisdictional claims in published maps and institutional affiliations.

Acknowledgements. The authors would like to thank the operators of the Niederweimar gravel quarry, as well as the Wissenschaftliche Baugrund-Archäologie e.V. (WiBA), namely Benedikt König for access to new excavations. Likewise, the authors would like to acknowledge the landowners for access to their land, as well as the handling editor and one anonymous referee for the improvement of our contribution.

Review statement. This paper was edited by Elisabeth Dietze and reviewed by one anonymous referee. 


\section{References}

Ad-hoc AG Boden: Bodenkundliche Kartieranleitung (Manual of soil mapping) (KA5), Bundesanstalt für Geowissenschaften und Rohstoffe, Hannover, Vol. 5, 438 pp., ISBN 9783510959204 , 2005.

Bos, J. A. A. and Urz, R.: Late Glacial and early Holocene environment in the middle Lahn river valley (Hessen, central-west Germany) and the local impact of early Mesolithic people - pollen and macrofossil evidence, Veg. Hist. Archaeobot., 12, 19-36, https://doi.org/10.1007/s00334-003-0006-7, 2003.

Durner, W., Iden, S. C., and von Unold, G.: The integral suspension pressure method (ISP) for precise particle-size analysis by gravitational sedimentation, Water Resour. Res., 53, 33-48, https://doi.org/10.1002/2016WR019830, 2017.

Freund, H. and Urz, R.: Ein frühweichselzeitliches Profil aus der Niederterrasse der mittleren Lahn (Weimar-Niederweimar, Hessen) - geologische, pollenanalytische und makrorestanalytische Untersuchungen. E\&G - Quaternary Sci. J., 50, A. 08, https://doi.org/10.23689/fidgeo-1332, 2000 (in German).

Hahn, J. and Opp, C.: Geochemische Eigenschaften von Laacher See-Tephra enthaltenden Bodensubstraten in eruptionsnaher underuptionsferner Position, Geol. Jb. Hessen 137, 65-77, 2011.
Jahn, R., Blume, H. P., Asio, V. B., Spaargaren, O., and Schad, P.: Guidelines for soil description, Food and Agriculture Organization of the United Nations (FAO), Rome, Vol. 4, 97 pp., ISBN 9789251055212, 2006.

Lomax, J., Steup, R., Shumilovskikh, L., Hoselmann, C., Sauer, D., van Diedenhoven, V., and Fuchs, M.: Field Trip B (27 September 2018): Quaternary environments of Giessen and its surrounding areas, DEUQUA Spec. Pub., 1, 15-28, https://doi.org/10.5194/deuquasp-1-15-2018, 2018.

Mäckel, R.: Untersuchungen zur jungquartären Flußgeschichte der Lahn in der Gießener Talweitung, E\&G Quaternary Sci. J., 20, 138-174, https://doi.org/10.3285/eg.20.1.14, 1969.

Van den Bogaard, P.: ${ }^{40} \mathrm{Ar} /{ }^{39} \mathrm{Ar}$ ages of sanidine phenocrysts from Laacher See Tephra (12,900 yr BP): Chronostratigraphic and petrological significance, Earth Planet. Sc. Lett, 133, 163-174, 1995.

Van den Bogaard, P. and Schminke, H. U.: Laacher See Tephra: A widespread isochronous Late Quaternary tephra layer in central and Northern Europe, Geol. Soc. Am. Bull., 96, 1554-1571, https://doi.org/10.1130/00167606(1985)96<1554:LSTAWI>2.0.CO;2, 1995. 